\title{
Minimally Invasive Flat Foot Alingment: A New Method
}

By Rodrigo Schroll Astolfi, Sarah Araújo Lima, Rayanne Carneiro Torres de Novaes, Henrique Cesar Temoteo Ribeiro, Alexandre Leme Godoy Santos

\& José Alberto Dias Leite

Abstract-Medializing calcaneal osteotomy is one of the most common procedures in flat foot alignment. Recently it has been done percutaneously with several different techniques, most of them made in lateral position. Our paper aims to describe the minimally invasive calcaneal medializing osteotomy in ventral position, easier for $x$-ray control, faster to patient positioning with technical tips to more precise bone cut and reduction. Between April 2019 and September 2019, 10 patients were operated using this technique. Patients in ventral position, sciatic nerve block, percutaneous Achilles lengthening, transcutaneous k-wire passage for drill cut control. Straight calcaneal cut, reduction in medial and plantar position and control both in lateral and axil views. 15 patients were operated using this technique. 67\% were woman. Median age were 38.9 years and median BMl was 23.5.

Keywords: flat foot, minimally invasive, hindfoot, medializing calcaneal, percutaneous.

Strictly as per the compliance and regulations of:

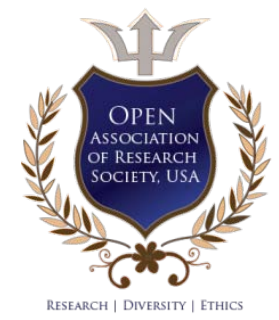

(c) 2020. Rodrigo Schroll Astolfi, Sarah Araújo Lima, Rayanne Carneiro Torres de Novaes, Henrique Cesar Temoteo Ribeiro, Alexandre Leme Godoy Santos \& José Alberto Dias Leite. This is a research/review paper, distributed under the terms of the Creative Commons Attribution-Noncommercial 3.0 Unported License http://creativecommons.org/licenses/by-nc/3.0/), permitting all non-commercial use, distribution, and reproduction in any medium, provided the original work is properly cited. 


\title{
Minimally Invasive Flat Foot Alingment: A New Method
}

\author{
Rodrigo Schroll Astolfi ${ }^{\alpha}$, Sarah Araújo Lima ${ }^{\circ}$, Rayanne Carneiro Torres de Novaes ${ }^{\circ}$, \\ Henrique Cesar Temoteo Ribeiro ${ }^{\omega}$, Alexandre Leme Godoy Santos ${ }^{*} \&$ José Alberto Dias Leite ${ }^{\S}$
}

Abstract-Medializing calcaneal osteotomy is one of the most common procedures in flat foot alignment. Recently it has been done percutaneously with several different techniques, most of them made in lateral position. Our paper aims to describe the minimally invasive calcaneal medializing osteotomy in ventral position, easier for $x$-ray control, faster to patient positioning with technical tips to more precise bone cut and reduction. Between April 2019 and September 2019, 10 patients were operated using this technique. Patients in ventral position, sciatic nerve block, percutaneous Achilles lengthening, transcutaneous k-wire passage for drill cut control. Straight calcaneal cut, reduction in medial and plantar position and control both in lateral and axil views. 15 patients were operated using this technique. $67 \%$ were woman. Median age were 38.9 years and median BMI was 23.5 .

All patients were able to bear full weight immediately. No cases of non-consolidation were observed, and consolidation occurred in all patients by 6 weeks as pain reduced, and initial signs of calcification could be detected in x-ray.

This is a descriptive paper with technical tips for percutaneous flat foot correction. Using these methods, the surgery becomes faster as patient position is the same for nerve block and for surgery, easier for calcaneal positioning in plantar and medial position, safer for drill use with the k-wire protection and easier for trans-operatively x-ray control. We also show some of the results before doing these modifications.

Keywords: flat foot, minimally invasive, hindfoot, medializing calcaneal, percutaneous.

\section{INTRODUCTION}

$\longrightarrow$ alcaneal osteotomy is a well-established surgery for flexible flat foot $(1,2)$. Many methods are possible and one of the most used is the calcaneal medial translation popularized by Kouktsogiannis (1), commonly associated with tendon transfer and spring ligament reconstruction. $(1,3,4,5)$.

Calcaneal medialization was usually made to favor the tendon transferred once the initial understanding was that the progressive flat foot in adults was secondarily to a tibialis posterior insufficiency. As tibialis posterior was the initial cause of the disease, it's substitution by a healthy despite weaker tendon was necessary. $(1,4,5,6,7,8,9)$.

Corresponding Author a: e-mail: dr.rodrigoastolfi@gmail.com
Some recent evidence has shown that in many cases, the disease starts as a ligamental insufficiency and the healthy tibialis posterior reacts trying to compensate and in a later pathology moment degenerate. $(1,5,8,10)$

This new understanding led to surgeries to address ligament reconstruction preserving tibialis posterior $(1,3,5,6,8)$ or isolated calcaneal osteotomies to give a better leaver arm for the tendon function $(11,12,13)$. Minimally invasive calcaneal osteotomy is one possible technique for flat foot correction with many possible advantages are earlier weight bearing and earlier consolidation. $(11,12,13)$

Most descriptions about this technique are made with the patient in lateral position with a lateral approach in a similar fashion as open techniques. $(11,12,13)$. This paper describes the minimally invasive technique made by one lateral or medial approach in a ventral position and our initial results.

\section{Methods}

Between April 2019 and September 2019, 10 patients were operated using this technique. Surgery is performed in ventral position under a sciatic nerve block. Consent was obtained and protocol was approved by local and national ethical committees. All patients have a percutaneous Achilles stretching. One kwire is inserted transcutaneously at the desired site for the osteotomy (figure 1). Lateral incision of about $5 \mathrm{~mm}$ large is made at the center of calcaneus.

A percutaneous periosteal elevator is inserted and only the line for the burr passage is dissected to allow minimal soft tissue disruption. The 2,5/20 mm Shannon burr is used. One dorsal to plantar direct and straight cut is made with the fluoroscopic visualization and the use of the k-wire as a guide for the cut. At this point an instrument can be inserted at the portal to leverage the fragment to in a plantar and medial direction or a Steinman 3.0 wire is passed near the Achilles insertion were a stronger bone is expected.

Lateral and axial views are easily performed in this position to check the ideal position for calcaneus and screws (figure 2).

Full weight bearing is permitted immediately. In 6 weeks strengthening exercises are initiated. 
15 patients were operated using this technique. $67 \%$ were woman. Median age were 38.9 years and median BMI was 23.5.

\section{UI. Results}

All patients were able to bear full weight immediately. More swelling and pain was seen in the younger patients.

No cases of non-consolidation were observed, and consolidation occurred in all patients by 6 weeks as pain reduced, and initial signs of calcification could be detected in X-ray.

No cases of infection, skin problems, nerve or vascular damage were detected, but two cases of proximal migration of distal fragment occurred before we adopted the Achilles lengthening in all patients.

\section{Discussion}

Painful flat foot is one of the most common orthopedics lesions in the elderly population, possibly because of progressive ligament insufficiency $(8,14)$. Once a valgus deformity is formed, non-conservative treatment has proved to correct definitively $(8,14)$. Bilateral flat foot has been associated with anterior knee pain, lumbar spine pain, besides hindfoot and ankle arthritis $(15,16)$.

Once the valgus alignment is present the deformity tends to evolve $(6,14,16,17,18)$. As population goes older because of the longer life expectation, severe cases of flat foot alignment tend to grow. Hindfoot arthritis are the next stage for these patients. Performing the calcaneal medializing correction can avoid this evolution $(13,16,19)$. So, the best time to perform the procedure is after deformity but before arthritis, which means that the patient should be addressed in a lifetime when short recovery procedures are fundamental for early return to work, your understanding is that minimally invasive corrections will play a fundamental role in this new reality.

In the older population, longer or more aggressive surgeries with longer rehabilitation protocols make many patients ineligibles. Minimally invasive surgery with only two punctual incisions, regional block and the possibility of immediate weight bearing may be the best solution for these patients as well.

When doing the traditional technique for flat foot correction (Jonhson's type 2), after the Kouktsogiannis osteotomy and flexor digitalis longus to navicular or tibialis posterior, our group felt that in most cases a health tibialis posterior was found only with some degree of fat degeneration and synovitis $(6,8)$. That impression went in the same direction of the recent literature, were the tibialis posterior insufficiency comes later after longer time of hindfoot progressive valgus alignment $(14,20)$. Thus, bone correction when a not completely degenerated tibialis posterior is seen in MRI is a possible and less aggressive choice in elderly population. (14)

This paper is addressed to show the ventral position used at these cases, which in our opinion makes the procedure easier. The nerve block is made already in the ventral position not needing to change patient position. Lateral and axial view of the calcaneus are made by only rotating the $\mathrm{C}$-arm.

Another differential of this position is that the medial approach can be made. In this surgery the greater risk is to injure the calcaneus branch of the tibial nerve, once it's the most posterior structure at medial side and is important for plantar sensibility. Laterally, several branches of the sural nerve are posterior, but they are responsible for a small not weight bearing area (21). This way, a medial approach gives a better control and protection of medial structures, and in lateral approach the incision is made in the traction side of the calcaneus, making it more difficult to heal. But we still need cadaveric studies to determine the safety.

We consider important the Achilles tendon stretching before the osteotomy. It makes the reduction easier; some similar articles show cases were the fragment makes a proximal migration (11). We consider the plantar positioning of the fragment to be essential for good correction. Thus, we observed less pain in patients submitted to the lengthening.

We had a clear impression that older patients are easier to operate, as the bone cut is softer, and they reported less pain in post operatory rehabilitation. So, this technique became our choice for patients over 50 years old.

\section{Conclusion}

We described a new technique approach for minimally invasive flat foot correction that seems easier, faster and more reliable for fluoroscopic control. Further comparative studies are necessary to see evolution of these patients.

Authors' contributions: This manuscript is the result of the co-work of the authors and the job distribution ocurred as follows:

RSA performed the surgeries, created the technique modifications and participated in the manuscript writing

SAL made the literature revision and manuscript final edition

HCTR was the second surgeon of the surgeries and participated of the technique modifications creation

ALGS was the final revisor of the manuscript and made the post operatopry data compitation

JADL was responsible for the manuscript edition and writing and literature revision. 


\section{References Références Referencias}

1. Jowett, C. R. J., Rodda, D., Amin, A., Bradshaw, A., \& Bedi, H. S. Minimally invasive calcaneal osteotomy: A cadaveric and clinical evaluation. Foot and Ankle Surgery 2016; 22(4), 244-.

2. Gleich A. Beitrag zur operativen Plattfussbehandlung. Arch Klin Chir 1893; 46:

3. Koutsogiannis E. Treatment of mobile flat foot by displacement osteotomy of the calcaneus. J Bone 2 Joint Surg Br 1971; 53: 96.

4. Guha AR, Perera AM. Calcaneal osteotomy in the treatment of adult acquired flatfoot deformity. Foot Ankle Clin 2012; 17: 247.

5. Silva MG, Tan SH, Chong HC, Su HC, Singh IR. Results of operative correction of grade IIB tibialis posterior tendon dysfunction. Foot Ankle Int 2015; 36: 165.

6. Wacker JT, Hennessy MS, Saxby TS. Calcaneal osteotomy and transfer of the tendon of flexor digitorum longus for stage-Il dysfunction of tibialis posterior, three- to five-year results. J Bone Joint Surg $\mathrm{Br}$ 2002;84:54. 318

7. Davitt JS, Beals TC, Bachus KN. The effects of medial and lateral displacement calcaneal osteotomies 5on ankle and subtalar joint pressure distribution. Foot Ankle Int 2001; 22: 885.

8. Schuh R, Gruber F, Wanivenhaus A, Hartig N, Windhager R, Trnka HJ. Flexor digitorum longus transfer and medial displacement calcaneal osteotomy for the treatment of stage II posterior tibial tendon dysfunction: kinematic and functional results of fifty one feet. Int Orthop 2013; 37: 1815.

9. Roberts, Lauren E. MD, MSc, FRCSC*; Ellis, Scott J. MD† The Collapsing Flatfoot: Bone Alignment, Bone Alignment, Bone Alignment!, Techniques in Foot \& Ankle Surgery: December 2019 - Volume 18 - Issue 4 - p 185-193.

10. Catanzariti AR, Lee MS, Mendicino RW. Posterior calcaneal displacement osteotomy for adult acquired flatfoot. J Foot Ankle Surg 2000; 39: 2.

11. Sherman TI, Guyton GP. Minimal Incision/Minimally Invasive Medializing Displacement Calcaneal Osteotomy. Foot Ankle Int. 2018 Jan; 39(1): 119-128. doi: 10.1177/1071100717744003. Epub 2017 Dec 14.

12. Lee M, Guyton GP, Zahoor T, Schon LC. Minimally Invasive Calcaneal Displacement Osteotomy Site using a Reference Kirschner Wire: A Technique Tip. J Foot Ankle Surg. 2016 Sep-Oct; 55(5): 11216. doi: 10.1053/j.jfas.2016.05.006. Epub 2016 Jun 7.

13. Arvinius C, Manrique E, Urda A, Cardoso Z, Galeote $J$ E, Marco F. A mid-term follow-up of Koutsogiannis' osteotomy in adult-acquired flatfoot stage II and "early stage III" SICOT J. 2017; 3: 24.
Published online 2017 Mar 17. doi: 10.1051/sicotj/ 2017011

14. Orozco-Villaseñor SL, Monzó-Planella M, MartínOliva X, Frias-Chimal JE, Mayagoitia-Vázquez JJ, Alvarado-Camacho SN. Biomechanical analysis through numerical simulation of rupture of the tibial posterior tendon in valgus flat foot: a cadeveric study. Acta Ortop Mex. 2018 Mar-Apr; 32(2): 82-87. Spanish.

15. Iijima H, Ohi H, Isho $\mathrm{T}$, AoyamaT, Kaneda E,Ohi K, Abe K, Kuroki H, Matsuda S. Association of bilateral flat feet with knee pain and disability in patients with knee osteoarthritis: A cross-sectional study. J Orthop Res.2017 Nov; 35(11): 2490-2498.

16. Cody, Elizabeth A. MD*; Younger, Alastair MB, ChB, MSc, ChM, FRCSC+; Cerrato, Rebecca A. MD‡; Johnson, A. Holly MD* The Flatfoot Through a Pinhole: Do It Percutaneously!, Techniques in Foot \& AnkleSurgery: December 2019 - Volume 18 Issue 4 - p 156-159.

17. Kendal AR, Khalid A, Ball $T$, Rogers M, Cooke $P$, Sharp R. Complications of minimally invasive calcaneal osteotomy versus open osteotomy. Foot Ankle Int 2015; 36: 685.

18. Dunham, Alexandra M. MD*; de Cesar Netto, Cesar $\mathrm{MD}, \mathrm{PhD}+, \ddagger$; Godoy-Santos, Alexandre L.§; Schon, Lew C. MD† 361 Should it Stay or Should it Go? Thinking Critically About Posterior Tibial Tendon Excision in Flatfoot Correction, Techniques in Foot \& Ankle Surgery: December 2019 - Volume 18 - Issue 4 - $p$ 166-173.

19. Chan JY, Williams BR, Nair P, Young E, Sofka C, Deland JT, et al. The contribution of medializing calcaneal osteotomy on hindfoot alignment in the reconstruction of the stage II adult acquired flatfoot deformity. Foot Ankle Int 2013; 34: 159.

20. Arangio G, Salathe E (2009) A biomechanical analysis of posterior tibial tendon dysfunction, medial displacement calcaneal osteotomy and flexor digitorum longus transfer in adult acquired flat foot. Clin Biomech 24(4), 385-390.

21. Durston A, Bahoo R, Kadambande S, Hariharan K, Mason L. Minimally Invasive Calcaneal Osteotomy: Does the Shannon Burr Endanger the Neurovascular Structures? A Cadaveric Study. J Foot Ankle Surg. 2015 Nov-Dec; 54(6): 1062-6. doi: 10.1053/j.jfas.2015.05.007. 


\section{Figure Legends}

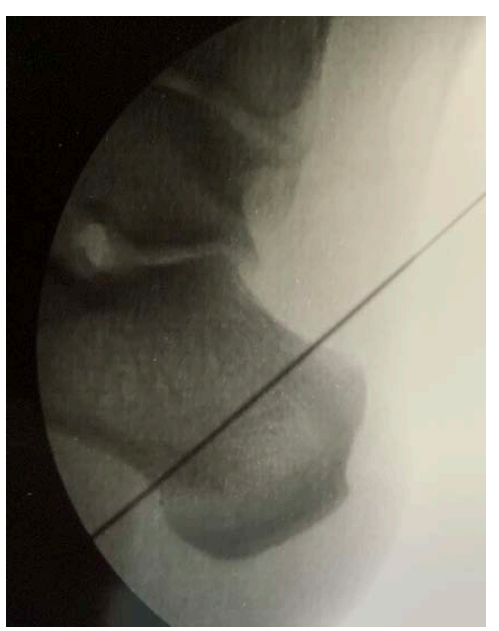

4 Figure 1: Guide k-wire inserted thought the skin lateral (if lateral incision) to the bone. The surgeon is able to feel it so a straight line is easier to do with the Shannon burr. K-wire is positioned in the limit of the "safe zone" which is half way between calcaneal spur and fibula.
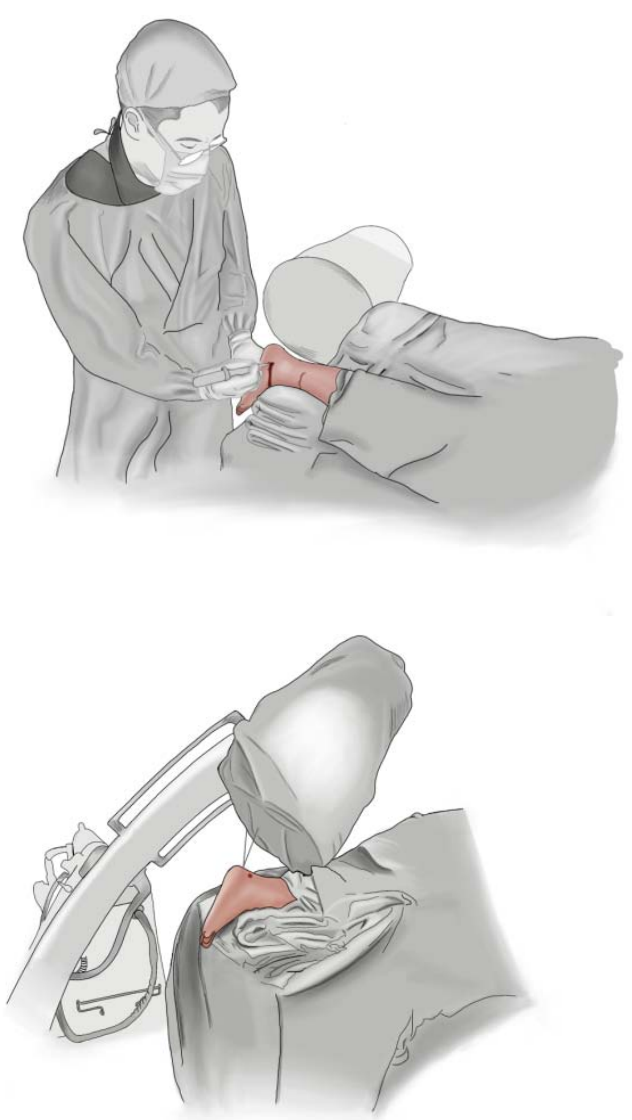

Figure 2: Intra-operatory Lateral and axial views. 